\title{
Experimental manipulation of colony genetic diversity had no effect on short-term task efficiency in the Argentine ant Linepithema humile
}

Received: 1 June 2004 / Revised: 1 November 2004 / Accepted: 23 November 2004 / Published online: 20 January 2005 (C) Springer-Verlag 2005

\begin{abstract}
Genetic diversity might increase the performance of social groups by improving task efficiency or disease resistance, but direct experimental tests of these hypotheses are rare. We manipulated the level of genetic diversity in colonies of the Argentine ant Linepithema humile, and then recorded the short-term task efficiency of these experimental colonies. The efficiency of low and high genetic diversity colonies did not differ significantly for any of the following tasks: exploring a new territory, foraging, moving to a new nest site, or removing corpses. The tests were powerful enough to detect large effects, but may have failed to detect small differences. Indeed, observed effect sizes were generally small, except for the time to create a trail during nest emigration. In addition, genetic diversity had no statistically significant impact on the number of workers, males and females produced by the colony, but these tests had low power. Higher genetic diversity also did not result in lower variance in task efficiency and productivity. In contrast to genetic diversity, colony size was positively correlated with the efficiency at performing most tasks and with colony productivity. Altogether, these results suggest that genetic diversity does not strongly improve short-term task efficiency in $L$. humile, but that worker number is a key factor determining the success of this invasive species.
\end{abstract}

Keywords Division of labour · Task efficiency · Genetic diversity $\cdot$ Social insects

Communicated by L. Sundström

H. Rosset · L. Keller · M. Chapuisat (®)

Department of Ecology and Evolution,

University of Lausanne,

Biology Building, 1015 Lausanne, Switzerland

e-mail: Michel.Chapuisat@unil.ch

Tel.: +41-21-6924178

Fax: +41-21-6924165

\section{Introduction}

Insect societies exhibit a great variability in social structure and overall level of genetic diversity (Crozier and Pamilo 1996). These variations can have profound implications for social interactions and group functioning (Bourke and Franks 1995; Keller and Chapuisat 2001). Both polygyny (the presence of multiple queens in the same colony) and polyandry (queens mating with multiple males) are widespread in the social insects (ants, bees, wasps and termites, Boomsma and Ratnieks 1996; Crozier and Pamilo 1996). Moreover, some ant populations are unicolonial, which means that individuals can mix freely among physically separated nests. The evolution of such complex social structures seems paradoxical at first, because the presence of multiple distantly related lineages decreases the indirect fitness benefits of cooperation and increases the potential for intracolonial conflicts (Keller and Chapuisat 1999; Queller and Strassmann 2002). However, the higher levels of genetic diversity that are associated with polyandry, polygyny and unicoloniality may also enhance colony productivity and survival, particularly if intracolonial genetic diversity improves task efficiency or disease resistance (Crozier and Page 1985; Keller and Reeve 1994; Schmid-Hempel and Crozier 1999; Crozier and Fjerdingstad 2001).

The task-efficiency hypothesis holds that genetic variation improves task performance through a more efficient division of labour (Robinson 1992). Division of labour is almost universal in the social insects, particularly in large societies (Oster and Wilson 1978). An increase in genetic diversity may allow a more complete expression of a genetically based caste system, thus leading to a more efficient worker force (Starr 1984). For example, if the response threshold for performing a task is genetically determined, genetically more diverse colonies may show a higher degree of behavioural specialisation (Beshers and Fewell 2001; Page and Erber 2002). Heritable differences in the probability of performing a task have been documented in many social insects, and some degree of genetic polyethism has been consistently de- 
tected in large colonies containing several matrilines or patrilines (e.g. Frumhoff and Baker 1988; Robinson and Page 1988; Stuart and Page 1991; Carlin et al. 1993; Oldroyd et al. 1994; Page et al. 1995; Julian and Cahan 1999; Costa and Ross 2003). Moreover, several recent studies found a genetic component to the determination of morphological castes in ants, thus raising the possibility that more diverse colonies may express a broader phenotypic variability (Fraser et al. 2000; Cahan et al. 2002; Julian et al. 2002; Volny and Gordon 2002; Cahan and Keller 2003; Hughes et al. 2003).

Although these data suggest that genetic diversity may increase task efficiency, direct tests of the hypothesis are still lacking. Some indirect evidence for the task-efficiency hypothesis was found in very small honeybee colonies, where the productivity measured over periods of 7-26 days tended to be higher in colonies with workers from multiple patrilines than in colonies with a single patriline (Fuchs and Schade 1994). However, the effect was either less pronounced, absent or dependent on patrilines combinations in studies of normal-sized colonies followed over longer time periods (Oldroyd et al. 1992; Fuchs and Schade 1994; Page et al. 1995). Moreover, diseases and parasites might also have had an effect on these measures of overall colony productivity. Therefore, to clarify the potential role of genetic diversity in improving task performance and division of labour, direct investigations of how workers from colonies with low and high genetic diversity actually perform tasks are needed.

An extension of the task-efficiency hypothesis is that higher genetic diversity might decrease the colony level variance in task performance and thus have an averaging effect on colony phenotype (Page et al. 1995). This might stabilise the colony behaviour and make it less prone to inappropriate response in changing environmental conditions (Page et al. 1995). Empirical support in favour of this hypothesis has been found in the honeybee. During the nest initiation phase, the performances of colonies with high genetic diversity tended to be average relative to colonies with low diversity (Page et al. 1995). Genetically more diverse colonies were also better than less diverse ones at maintaining a stable temperature in their nest (Jones et al. 2004).

The disease-resistance hypothesis holds that colonies with genetically more diverse individuals should be more resistant to parasites and pathogens because they have a lower variance in disease susceptibility and are more likely to contain resistant individuals (Sherman et al. 1988). Strong support for this hypothesis has been found in experimental studies of bumblebees (Liersch and Schmid-Hempel 1998; Baer and Schmid-Hempel 1999, 2001), honeybees (Palmer and Oldroyd 2003; Tarpy 2003), and leaf-cutting ants (Hughes and Boomsma 2004). However, the general importance of genetic diversity in improving disease resistance in wild colonies of social Hymenoptera remains debated (Kraus and Page 1998; Sherman et al. 1998).

Several studies have also tested whether genetic diversity is correlated with colony performance without distinguishing between the task-efficiency and the disease-resistance hypotheses. The outcomes of these studies were highly variable. Genetically more diverse colonies of the harvester ant Pogonomyrmex occidentalis had higher growth rates and survival (Cole and Wiernasz 1999; Wiernasz et al. 2004). In contrast, colony genetic diversity was not correlated with individual growth rate or survival in tent caterpillars (Costa and Ross 2003), with productivity or colony size in two species of ants (Sundström and Ratnieks 1998; Fjerdingstad et al. 2003), or with colony performance in honeybee colonies headed by naturally mated queens (Neumann and Moritz 2000). More powerful, causal studies in which genetic diversity was experimentally manipulated are very few. Bumblebee colonies with multiple patrilines were much more productive than colonies with a single patriline, and they also had a lower load of parasites (Baer and Schmid-Hempel 1999). In honeybee colonies, genetic diversity sometimes had no effect on colony performance, and sometimes either positive or negative effects depending on genotypes, task and colony size (Oldroyd et al. 1992; Fuchs and Schade 1994; Page et al. 1995). Overall, the general importance of genetic diversity in increasing productivity and survival of social-insect colonies remains debated, and the respective roles of task efficiency and parasite resistance are still unclear. To resolve this issue, the direct effect of genetic diversity should be experimentally tested in more species and in diverse ecological conditions.

Here, we experimentally tested the task-efficiency hypothesis in the Argentine ant Linepithema humile. This invasive species has been inadvertently introduced from South America into many regions with a Mediterranean or subtropical climate all over the world (Suarez et al. 2001). The species underwent a bottleneck during introduction, but the loss of genetic diversity was moderate compared to the native population, and there is still a large amount of gene diversity in Europe (Giraud et al. 2002). In both the native and introduced ranges, there is a significant amount of genetic variation within each nest (Krieger and Keller 2000; Tsutsui and Case 2001). In the native range in Argentina, the within-colony relatedness is moderate on average (mean $=0.4$, Tsutsui and Case 2001), the number of queens and amount of genetic diversity vary among nests and colonies, and some populations are unicolonial, which means that workers and queens can move freely within networks of nests without eliciting aggression (J.S. Pedersen, M.J.B. Krieger, T. Giraud and L. Keller, unpublished data). In the introduced range, the average within-nest relatedness is close to zero (Krieger and Keller 2000; Tsutsui and Suarez 2003), many queens reproduce in each nest, and the species forms very large unicolonial populations (supercolonies, Giraud et al. 2002; Holway et al. 2002; Ingram 2002).

Argentine ants are very efficient at performing various tasks, such as recruiting nestmates to a food source, foraging, moving nest sites, attacking competitors or raiding the nests of other species (Human and Gordon 1996, 1999; Holway 1999; Holway et al. 2002). There is also experimental evidence that entire groups of workers tend 
to specialise on certain tasks and that nests are moved depending on colony needs (Holway and Case 2000). Because L. humile is such an efficient competitor and coloniser, it quickly became an ecologically dominant species that displaced other ants and disrupted the native arthropod fauna over large areas of its introduced range (Holway et al. 2002).

In this experiment, we tested if genetic diversity had a large impact on task efficiency in L. humile. We experimentally created low and high genetic diversity colonies. We then compared the short-term efficiency of both types of colonies at performing four tasks that are likely to be important to the colony fitness: exploration of a new territory, food collection, nest moving and corpse removal. The task-efficiency hypothesis predicts that colonies with higher genetic diversity should be more efficient and exhibit a lower variance when performing specific tasks. In addition to these short-term measures of task efficiency, we also recorded the production of workers, males and queens. The task-efficiency hypothesis predicts that overall productivity should be greater and less variable in genetically more diverse colonies. Higher productivity in more diverse colonies is also predicted by the disease-resistance hypothesis, but only if the cost of parasites is high in experimental conditions.

\section{Methods}

Field collection and rearing conditions

Large numbers of queens and workers from the Argentine ant $L$. humile were collected on 1 March 1999 in Port Leucate (France) and mixed into a few large stock colonies. Experimental colonies were housed in artificial nests as described by Passera et al. (1988), fed twice a week with $8 \%$ sugar water, mealworms and a synthetic diet (Keller et al. 1989a) and kept at $27 \pm 2^{\circ} \mathrm{C}$ with a $15 \mathrm{~h} / 9 \mathrm{~h}$ light/ dark regime.

Low and high genetic diversity colonies

We experimentally produced low genetic diversity colonies composed of workers from a single queen, and high genetic diversity colonies composed of a mix of workers from at least four queens. We first created colonies with 1 queen and 100 unrelated workers but no brood. The initial addition of workers is necessary because L. humile queens cannot found nests independently and need workers to rear their brood. After 4 weeks, we reduced the number of unrelated workers to 30 and started the experimental manipulation of colony genetic diversity.

Low genetic diversity colonies consisted of a single queen and her worker daughters. In this treatment, brood was manipulated as in the high diversity treatment, but was put back into its colony of origin. High genetic diversity colonies also had a single queen, but we performed repeated cross-fostering of either eggs (eggs-transferred treatment) or pupae (pupae-transferred treatment) between colonies. Colonies were organised in blocks of four. Within each block, brood was exchanged between pairs of colonies, in switching combinations. Brood exchange took place every 2 weeks, over a period of 30 weeks. Hence, at the end of the treatment, each colony had exchanged brood on five occasions with each of the three other colonies in the same block. During each exchange, a number of brood items equal to half the mean number of brood present in the two colonies was taken from each colony and transferred into the other colony. This procedure permits one to manipulate brood composition without affecting brood size. The 2 -weeks interval between exchange events ensured that eggs or pupae were transferred only once, as under our standard laboratory conditions, both the egg and pupa stages last for approximately 14 days (Benois 1973).

A significant proportion of queens died during the experiment, but the mortality did not differ significantly among the 3 treatment groups $(9,14$ and 15 queens died in the low-diversity, egg-transferred and pupae-transferred treatment groups, respectively; $\mathrm{chi}^{2}$ goodness-of-fit: $d f=2, \mathrm{chi}^{2}=0.85, P=0.65$ ). Ten other colonies had to be discarded because they had produced fewer than 20 pupae after 4 weeks (5, 3 and 2 of these colonies belonged to the lowdiversity, egg-transferred and pupae-transferred treatment groups, respectively; chi $^{2}$-goodness-of-fit: $d f=2, \operatorname{chi}^{2}=0.64, P=0.73$ ). The reasons for the high mortality and low productivity of queens are not known, but at this time of the year, queens do also have a very high mortality and low fertility in the field (Benois 1973; Keller et al. 1989b).

If a queen died, the colony was discarded, and another singlequeen colony was used to supply brood to the other colonies, without being included in performance tests. Hence, at the end of the brood-rearing and cross-fostering period, each high-diversity colony had received a known number of brood items from at least four queens. We succeeded in experimentally producing 16 low genetic diversity colonies and 20 high genetic diversity colonies, of which 9 were obtained by transferring eggs and 11 by transferring pupae. The 20 high genetic diversity colonies belonged to 10 independent blocks of colonies that had exchanged brood.

Estimating genetic diversity

The genetic diversity was estimated by three different methods. First, we estimated the relatedness in each colony from the proportion of brood exchanged between colonies, using the formula

$r=\frac{3}{4} \sum_{i=1}^{n} P_{i}^{2}$

in which $r$ is the average relatedness among workers in a given colony and $P_{i}$ the proportion of workers that are the offspring of the $i^{\text {th }}$ queen. The average relatedness within a treatment group is simply the average relatedness over all colonies in this treatment group. This procedure is based on the assumptions that queens mate with a single male, and that reproductive individuals (nestmate queens and males) are unrelated. Genetic data showed that these assumptions are satisfied in the study population (Krieger and Keller 2000).

Second, relatedness was measured with genetic markers. We genotyped six adult workers per colony at four polymorphic microsatellite loci (Lhum11, Lhum13, Lhum19, Lhum35, Krieger and Keller 1999). Regression relatedness was estimated with the computer program relatedness 5.0.8 (Queller and Goodnight 1989, available at http://www.gsoftnet.us/GSoft.html), weighting nests equally. Background population allele frequencies used for computation came from a large sample of Port Leucate population (Krieger and Keller 2000, J.S. Pedersen, unpublished data). Standard errors were obtained by jack-knifing over colonies.

Third, using the same microsatellite data set, we estimated the allelic richness per locus in each colony, which is a measure of the number of alleles independent of sample size (El Mousadik and Petit 1996). Estimates of allelic richness were obtained with the computer program FSTAT 2.9.3 (Goudet 1995, available at http:// www2.unil.ch/popgen/softwares/fstat.htm).

\section{Colony efficiency}

We assessed the short-term efficiency of low and high genetic diversity colonies at performing four tasks. We also estimated the long-term productivity of colonies by measuring their production of 
Fig. 1 Experimental setup to measure task efficiency. a Exploration. b Foraging. c Nest moving. d Corpse removal. a.
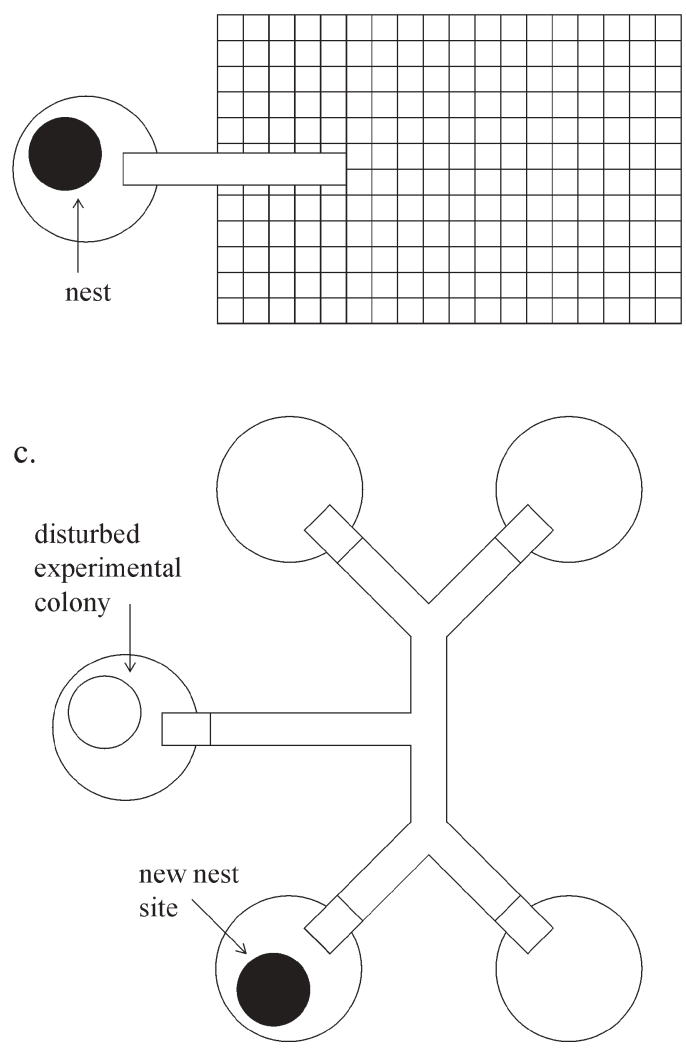

b.

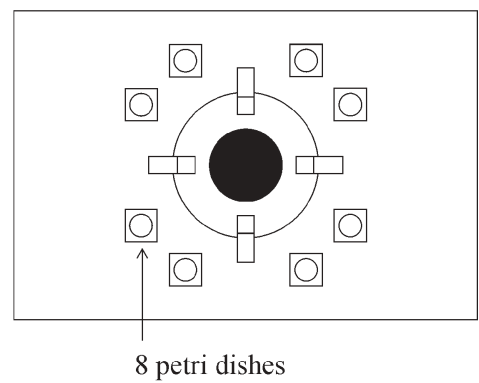

d.

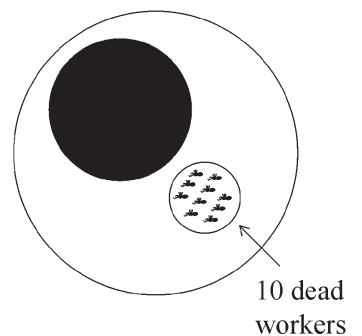

workers, queens and males. For each task, all colonies were tested at the same age, that is, the same number of days after colony initiation. The four tasks were tested sequentially between August and October, and the productivity of colonies was assessed last, in November 1999. Colonies were food-deprived for $24 \mathrm{~h}$ before the beginning of the exploration, nest-moving and corpse-removal experiments, and for $72 \mathrm{~h}$ before the foraging experiment.

In the first experiment, we measured the rate at which colonies explored a new area. The experiment started when we connected a bridge between the colony and a new arena $(480 \times 330 \mathrm{~mm}$, gridded into 26-mm squares, Fig. 1a). The progression of exploration was video-recorded during $4 \mathrm{~h}$ and assessed by counting the proportion of squares that had been visited by ants. The exploration efficiency was estimated as the time necessary to explore the area comprising between 10 and $90 \%$ of the arena. We started to record time after the first $10 \%$ of the arena had been explored because placing the bridge disturbed the colonies and added some variance to the initial phase of exploration.

In the second experiment, we estimated the efficiency of colonies at retrieving food when foraging. Each colony was placed into a foraging arena $(480 \times 330 \mathrm{~mm})$ for $72 \mathrm{~h}$ before the beginning of the experiment, so that ants could explore the new arena (Fig. 1b). We started the experiment by adding eight petri dishes $(\emptyset$ : $45 \mathrm{~mm}$ ) around the colony. Two of the petri dishes, randomly chosen, held $300 \mu \mathrm{l}$ of $10 \%$ sugar water (Fig. 1b). The experiment lasted $4 \mathrm{~h}$ and was video-recorded. Food consumption was estimated by weighing sugar-water petri dishes before and after the experiment, and subtracting the weight loss due to evaporation, which was estimated using four petri dishes placed around the foraging area. The maximum number of workers recruited to the food source and the time between food discovery and this maximum recruitment were also recorded.

In the third experiment, we recorded colony efficiency in moving the nest during emigration. L. humile is a tramp species accustomed to move to new nest sites when perturbations occur or when abiotic conditions such as humidity, temperature or darkness become disadvantageous (Passera 1994). We experimentally induced nest emigration by removing the black cover of the nest, thus placing colonies in daylight. Simultaneously, we placed a bridge connecting the colony to four new arenas ( $\varnothing: 154 \mathrm{~mm}$ ), one of which contained a new nest under a black cover (Fig. 1c). The experiment lasted for $2 \mathrm{~h}$ and was video-recorded. We first measured the time needed to initiate the migration trail and then the subsequent duration of nest moving, estimated as the time from trail establishment to the maximum of the peak of traffic that occurs in the middle of moving.

In the fourth experiment, we measured the speed at which corpses of workers were removed. We put small petri dishes $(\varnothing$ : $40 \mathrm{~mm}$ ) in front of the nest entrance of the experimental colonies for several days before the start of the experiment to permit familiarisation (Fig. 1d). At the start of the experiment, the corpses of ten workers were placed into the petri dishes. These dead workers came from stock colonies. They were killed by freezing and defrosted $2 \mathrm{~h}$ prior to the start of the experiment. Every $3 \mathrm{~min}$, we recorded the number of dead workers remaining in the petri dish. The efficiency of corpse removal was estimated as the time necessary to remove $90 \%$ of the corpses.

In the last set of experiments, we estimated colony productivity in terms of number of new workers, queens and males reared. First, we recorded the number of worker larvae produced during 12 weeks, while the colonies were still queenright. The ratio between the number of larvae reared by workers and the number of eggs laid by the queen during the same period was also estimated. Second, we estimated the production of new queens and males. Upon orphaning, L. humile workers start producing new winged queens and males at any time of the year (Vargo and Passera 1991). We removed all queens from experimental colonies, and recorded the total number of new queens and males produced per colony until all pieces of brood had completed their development. We also estimated the total amount of energy invested into queens and 
Table 1 Mean relatedness, allelic richness and size of experimental colonies $( \pm \mathrm{SE})$

\begin{tabular}{|c|c|c|c|c|c|}
\hline \multirow[t]{2}{*}{ Treatment } & \multirow[t]{2}{*}{$n$} & \multicolumn{2}{|l|}{ Colony relatedness } & \multirow{2}{*}{$\begin{array}{l}\text { Allelic } \\
\text { richness }\end{array}$} & \multirow{2}{*}{$\begin{array}{l}\text { Colony size } \\
\text { (number of } \\
\text { workers) }\end{array}$} \\
\hline & & $\begin{array}{l}\text { Based on the proportion } \\
\text { of brood exchanged }\end{array}$ & $\begin{array}{l}\text { Based on microsatellite } \\
\text { markers }\end{array}$ & & \\
\hline Low genetic diversity & 16 & 0.75 & $0.66 \pm 0.07$ & $1.84 \pm 0.09$ & $148 \pm 16$ \\
\hline $\begin{array}{l}\text { High genetic diversity } \\
\text { (egg-transferred) }\end{array}$ & 9 & $0.41 \pm 0.03$ & $0.34 \pm 0.10$ & $2.21 \pm 0.13$ & $184 \pm 53$ \\
\hline $\begin{array}{l}\text { High genetic diversity } \\
\text { (pupae-transferred) }\end{array}$ & 11 & $0.41 \pm 0.05$ & $0.49 \pm 0.12$ & $1.97 \pm 0.11$ & $206 \pm 53$ \\
\hline $\begin{array}{l}\text { High genetic diversity } \\
\text { (total) }\end{array}$ & 20 & $0.41 \pm 0.03$ & $0.43 \pm 0.08$ & $2.08 \pm 0.08$ & $196 \pm 37$ \\
\hline
\end{tabular}

males, relative to the energy needed to produce one male. Therefore, we multiplied the number of queens by their relative cost of production, which is 2.4 times the cost of a male (Passera and Keller 1987).

Statistical analysis

The effect of genetic diversity on task efficiency and colony productivity was tested in an analysis of covariance (Ancova), with colony size as a covariate. To normalise the data, log transformation was used for continuous data and angular transformation for percentages. As 12 different measures of performance were tested, the usual significance thresholds were adjusted with a sequential Bonferroni procedure (Rice 1989). Because of cross-fostering, colonies within blocks shared the same source of workers and thus were not fully independent. This possible source of pseudo-replication was controlled for by doing all the Ancovas and subsequent analyses of power with only one single average value for each block of four colonies that had exchanged brood.

We assessed the power of our analysis by determining the probability of detecting an increase of $40 \%$ in task efficiency or colony productivity. For each measure, we simulated a $40 \%$ difference between low and high genetic diversity colonies. We then calculated the power of detecting such an increase in performance with the computer program GPOWER (Erdfelder et al. 1996, available at http://www.psycho.uni-duesseldorf.de/aap/projects/ gpower/index.html). Moreover, we calculated the relative difference between high and low genetic diversity treatment ((high-diversity performance-low-diversity performance)/low-diversity performance), as well as the observed effect size $f$ described by Cohen (1988). In both measures, we controlled for colony size by using the residuals of task or productivity on colony size.

To examine if an increase in genetic diversity reduces the variance in task efficiency or colony productivity, we performed $F$ tests of variance between the low and high genetic diversity colonies. In this test, the $F$-value is defined as the variance of lowdiversity colonies divided by the variance of high-diversity colonies. To control for the effect of colony size, the performance was first regressed on colony size, and the test of variance was then applied on the residuals of this regression. Each colony was considered independently because averaging values per block may artificially lower the variance of colonies that had exchanged brood.

\section{Results}

There was no significant difference in relatedness or allelic richness between the egg-transferred and pupaetransferred colonies (Table 1; relatedness based on the proportion of brood exchanged: two-tailed $t$-test, $t=0.09$, $d f=18, P=0.93$; relatedness based on microsatellites: twotailed $t$-test, $t=0.96, d f=18, P=0.35$; allelic richness: two- tailed $t$-test, $t=1.44, d f=18, P=0.17)$. Moreover, considering egg-transferred and pupae-transferred colonies separately or together returned qualitatively similar results for all analyses of task efficiency and colony productivity (considering three treatment groups instead of two did return the same sets of significant and non-significant factors in the Ancova analysis, see below). Therefore, to increase the power of further analyses, egg-transferred and pupae-transferred colonies were considered together in a single high genetic diversity treatment group.

\section{Genetic diversity of colonies}

The colony relatedness estimated from the proportion of brood transferred was similar to the one measured with microsatellite markers (Table 1; low genetic diversity colonies: Wilcoxon rank test, $Z=1.27, n_{\text {prop.brood }}=16$, $n_{\text {microsatellite }}=16, P=0.20$; high genetic diversity colonies: two-tailed $t$-test, $d f=38, t=0.25, P=0.80)$. The congruence between the two methods indicates that experimentally transferred brood was actually accepted and reared as nestmate brood.

Colonies that had received the high genetic diversity treatment had a significantly lower relatedness and a significantly higher allelic richness than colonies from the low genetic diversity group, confirming that the treatment had the expected effect on genetic diversity (Table 1; relatedness based on proportion of brood transferred: Wilcoxon rank test, $Z=5.32, n_{\mathrm{HD}}=20, n_{\mathrm{LD}}=16, P<0.001$; relatedness based on microsatellites: one-tailed $t$-test, $t=2.14, d f=34, P=0.019$; allelic richness, one-tailed $t$-test, $t=1.99, d f=34, P=0.028)$. Hence, the cross-fostering procedure was efficient in generating colonies with significantly higher genetic diversity than colonies without brood exchange.

\section{Colony size}

The number of workers did not differ significantly between low and high genetic diversity colonies (Table 1; two-tailed $t$-test, $t=1.09, d f=34, P=0.28)$. However, the power of this test was very low (0.22). Colony size was highly variable, and the variance was larger in colonies with high genetic diversity than in colonies with low 

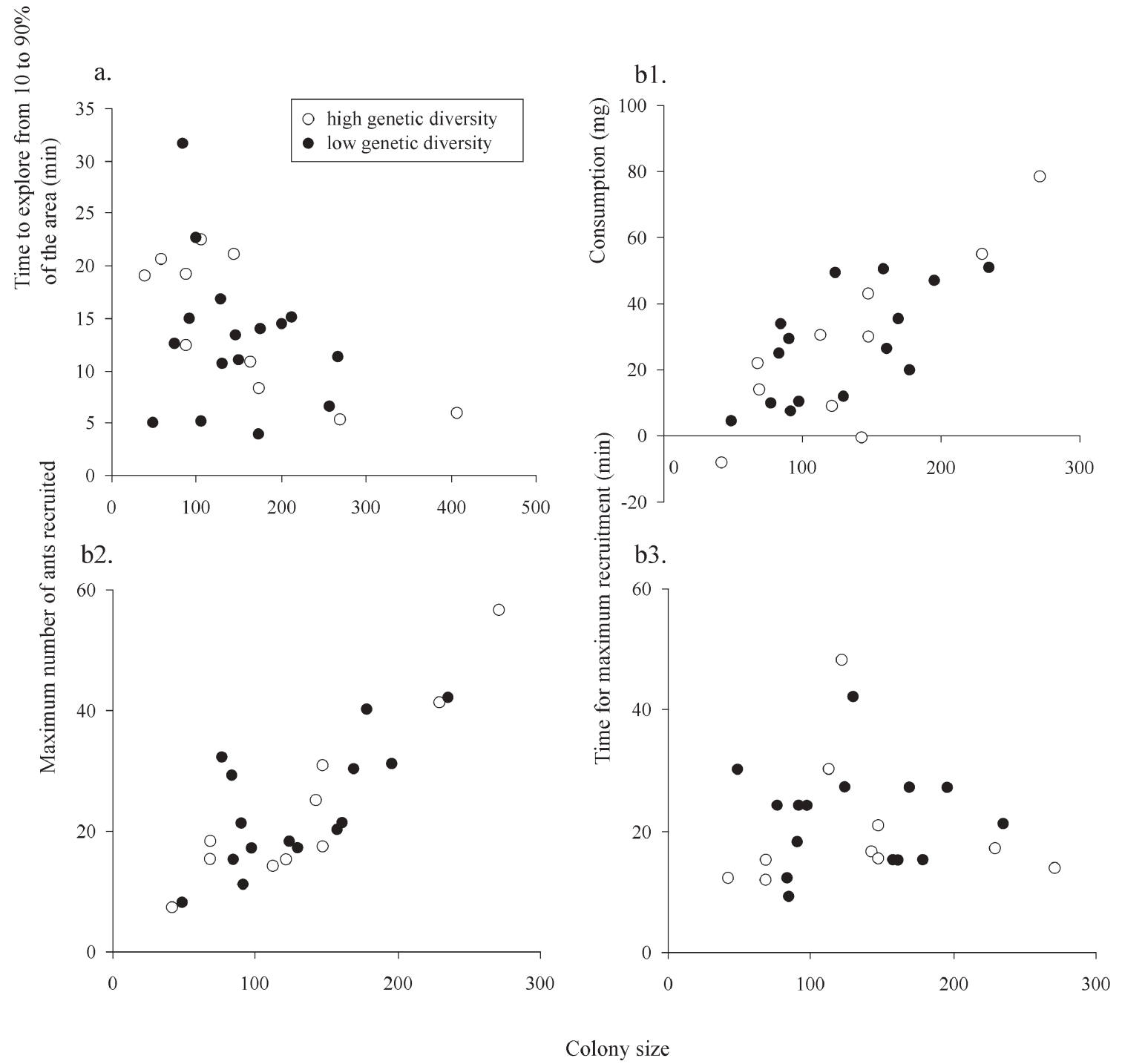

Fig. 2 a Exploration efficiency of colonies with low and high genetic diversity as a function of colony size. b Foraging efficiency of colonies with low and high genetic diversity as a function of colony

genetic diversity ( $F$ test of variance, $F=3.68, d f_{\mathrm{HD}}=19$, $\left.d f_{\mathrm{LD}}=15, P=0.013\right)$. We controlled for colony size in all analyses of colony efficiency.

Impact of genetic diversity on colony efficiency

For each of the four tasks tested in short-term trials, there was no significant difference between the efficiency of low and high genetic diversity colonies, even before Bonferroni adjustment (Figs. 2, 3, Table 2). Hence, the level of genetic diversity had no major impact on colony efficiency when exploring a new territory, foraging, moving to a new nest site, or removing corpses, whatever the indicator of efficiency (Table 2). For all indicators of short-term task efficiency, the power analysis revealed that an increase in colony efficiency of $40 \%$ would have been detected with a probability ranging from 0.71 to 1.0

size. b1 Consumption. b2 Maximum number of ants recruited. b3 Time between food discovery and maximum recruitment.

(Table 2). The observed differences in task efficiency between high- and low-diversity treatments ranged from 0 to $9 \%$, and the effect sizes were generally small to moderate, except for the time to create a trail during nest emigration, which had a large effect size (Table 2).

Colony productivity did not differ significantly between low and high genetic diversity colonies (Fig. 4, Table 2). When queenright, the two types of colonies did not differ significantly in the number of worker larvae produced, or in the proportion of eggs that were reared as larvae. When the queens were experimentally removed, genetic diversity had no statistically significant impact on the number of queens and males produced, or in the total amount of energy invested into the production of queens and males. However, all these tests on colony productivity had very low power (Table 2), because a high proportion of colonies produced few or no brood in both the low and high genetic diversity treatments (Fig. 4). 


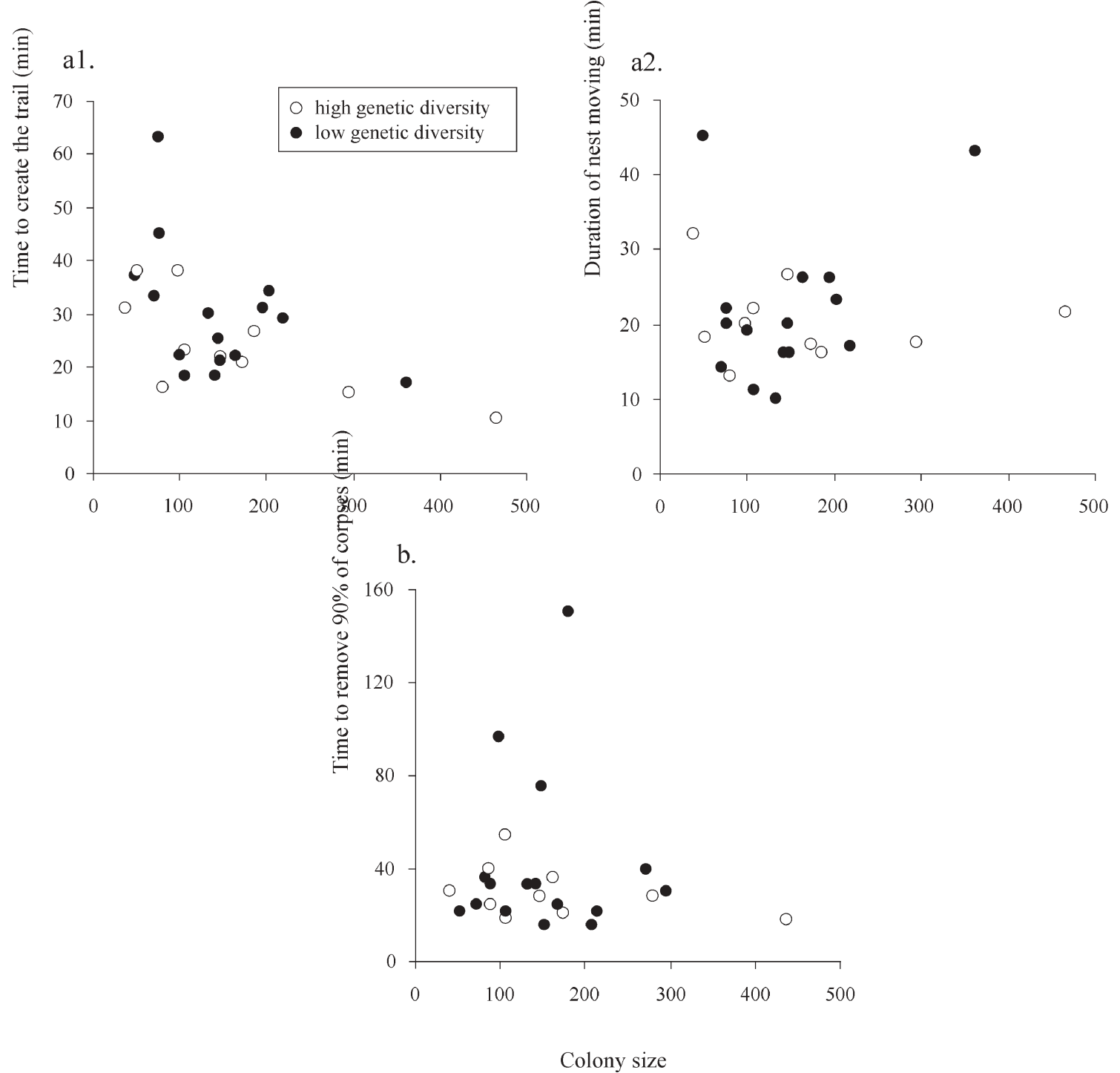

Fig. 3 a Nest-moving efficiency of colonies with low and high genetic diversity as a function of colony size. a1 Time to create the migration trail. a2 Duration of nest moving. b Corpse-removal

Colonies with low and high genetic diversity had similar levels of variance in task efficiency and productivity, with all tests being far from significant even before the Bonferroni adjustment (Table 3). This absence of significant difference was confirmed in an analysis of variance homogeneity (Bartlett test, $P$-values ranged from 0.11 to 0.95 ). Moreover, no pattern was detected in the overall data set, as the variance of low-diversity colonies was greater than the one of high-diversity colonies in seven tests and smaller in five other tests (Table 3). Very similar results were also obtained when four extremesized colonies of the high genetic diversity group were removed prior to the tests in order to obtain a similar variance of colony size in low and high genetic diversity groups ( $F$ test of variance, $F=1.84, d f_{\mathrm{HD}}=15, d f_{\mathrm{LD}}=15$, $P=0.25)$ : all tests remained non-significant, with $P$-values ranging from 0.08 to 0.94 . efficiency of colonies with low and high genetic diversity as a function of colony size.

Correlation between colony size and efficiency

A significant positive correlation between colony size and performance was detected for 8 out of the 12 indicators of task efficiency and colony productivity, and these 8 tests remained significant after applying the sequential Bonferroni adjustment for multiple comparisons (Table 2). Overall, larger colonies collected more sugar water, recruited a larger number of workers to the food source, and were quicker to create a migration trail (Figs. 2, 3, Table 2). However, colony size did not correlate with either the per-capita efficiency in collecting sugar water (Spearman rank correlation, $S=2104, n=24, P=0.75$ ), or with the percentage of workers recruited at the baits $(S=2982, n=25, P=0.48)$. Moreover, colony size was not significantly correlated with the time to explore a new area, the time between food discovery and maximal re- 
Table 2 Ancova on measures of performance as a function of genetic diversity, with colony size as a covariate. Significance levels after a sequential Bonferroni adjustment are indicated with stars $(* P<0.05$; ** $P<0.01 ; * * * P<0.001)$. "Power" is the probability to detect an increase of $40 \%$ in colony performance; "difference between treatments" is the relative difference between high and low genetic diversity treatments, and "effect size" is the observed effect size $f$ (Cohen 1988)

\begin{tabular}{|c|c|c|c|c|c|c|c|c|c|}
\hline \multirow[t]{3}{*}{ Task } & \multicolumn{6}{|c|}{ Ancova } & \multirow{2}{*}{\multicolumn{3}{|c|}{ Genetic diversity }} \\
\hline & \multicolumn{2}{|c|}{ Genetic diversity } & \multicolumn{2}{|c|}{ Colony size } & \multicolumn{2}{|c|}{ Interaction } & & & \\
\hline & $F_{1,23}$ & $P$ & $\overline{F_{1,23}}$ & $P$ & $\overline{F_{1,22}}$ & $P$ & Power & $\begin{array}{l}\text { Difference } \\
\text { between } \\
\text { treatments }\end{array}$ & Effect size \\
\hline \multicolumn{10}{|l|}{ Exploration } \\
\hline Time to explore the area & 0.29 & 0.59 & 4.23 & 0.05 & 2.38 & 0.14 & 0.77 & +0.01 & 0.10 \\
\hline \multicolumn{10}{|l|}{ Foraging } \\
\hline $\begin{array}{l}\text { Maximum number } \\
\text { of ants recruited }\end{array}$ & 0.14 & 0.71 & 36.45 & $4 \cdot 10^{-6 * * *}$ & 0.53 & 0.48 & 0.73 & -0.02 & 0.08 \\
\hline $\begin{array}{l}\text { Time for maximum } \\
\text { recruitment }\end{array}$ & 0.55 & 0.47 & 0.27 & 0.61 & 0.15 & 0.70 & 0.82 & -0.09 & 0.24 \\
\hline \multicolumn{10}{|l|}{ Nest moving } \\
\hline Time to create the trail & 3.43 & 0.08 & 15.49 & $7 \cdot 10^{-4 * *}$ & 0.04 & 0.84 & 0.98 & -0.07 & 0.39 \\
\hline Duration of nest moving & 0.01 & 0.93 & $10^{-4}$ & 0.99 & 0.52 & 0.48 & 0.95 & 0.00 & 0.02 \\
\hline Number of worker larvae & 0.06 & 0.81 & 15.77 & $6 \cdot 10^{-4 * *}$ & 0.92 & 0.35 & 0.08 & +0.03 & 0.05 \\
\hline $\begin{array}{l}\text { Larvae to eggs ratio } \\
\text { (2) Production of queens } \\
\text { and males }\end{array}$ & 0.55 & 0.46 & 8.12 & $9 \cdot 10^{-3 *}$ & 0.62 & 0.45 & 0.20 & +0.15 & 0.17 \\
\hline Number of males & 1.62 & 0.22 & 20.70 & $2 \cdot 10^{-4 * *}$ & 0.37 & 0.55 & 0.11 & +0.36 & 0.28 \\
\hline Number of queens & 0.12 & 0.74 & 19.75 & $2 \cdot 10^{-4 * *}$ & 0.36 & 0.55 & 0.12 & +0.14 & 0.07 \\
\hline $\begin{array}{l}\text { Investment in queens } \\
\text { and males }\end{array}$ & 0.52 & 0.48 & 30.20 & $2 \cdot 10^{-5 * * *}$ & $2 \cdot 10^{-3}$ & 0.97 & 0.10 & +0.18 & 0.16 \\
\hline
\end{tabular}

cruitment, the duration of nest moving, and the speed at which corpses were removed (Figs. 2, 3, Table 2).

In absolute terms, larger colonies produced significantly more workers, queens and males (Fig. 4, Table 2). Moreover, the ratio of the number of larvae reared to the number of eggs laid was higher in larger colonies (Table 2). Importantly, the per-capita efficiency was positively correlated with colony size for the production of workers $(S=1380, n=25, P=0.02$, Fig. 4), males $(S=1211$, $n=25, P=0.007)$, queens $(S=1053, n=25, P=0.002)$ and total investment in queens and males $(S=940, n=25, P$ $<0.001$, Fig. 4).

\section{Discussion}

This study provides the first direct experimental test of the task-efficiency hypothesis, which holds that genetic variation improves the performance of social groups through a more efficient division of labour (Starr 1984). We manipulated the level of genetic diversity in laboratory colonies of the Argentine ant L. humile, and tested if colonies with higher genetic diversity were more efficient when performing four tasks that are likely to be important for fitness under natural conditions. Low and high genetic diversity colonies showed no major and significant difference in efficiency when exploring a new territory, foraging, moving to a new nest site, or removing corpses.
Table $3 F$ tests of variance between low and high genetic diversity colonies applied on the residuals of the regression with colony size. $F$-values are the ratio of the variance of low genetic diversity colonies $(d f=15)$ over the variance of high genetic diversity colonies $(d f=19)$. None of the tests were significant even before a Bonferroni adjustment

\begin{tabular}{lll}
\hline Task & \multicolumn{2}{l}{ Genetic diversity } \\
\cline { 2 - 3 } & $F$-ratio & $P$ \\
\hline $\begin{array}{l}\text { Exploration } \\
\quad \text { Time to explore the area }\end{array}$ & 2.20 & 0.11 \\
$\begin{array}{l}\text { Foraging } \\
\quad \text { Consumption }\end{array}$ & 1.36 & 0.55 \\
$\quad \begin{array}{l}\text { Maximum number of ants recruited } \\
\text { Time for maximum recruitment }\end{array}$ & 1.14 & 0.78 \\
$\quad$ Nest moving & 0.58 & 0.30 \\
$\quad \begin{array}{l}\text { Time to create the trail } \\
\text { Duration of nest moving }\end{array}$ & 0.71 & 0.53 \\
$\quad$ Corpse removal & 0.80 & 0.67 \\
$\quad$ Time to remove the corpses & 2.07 & 0.14 \\
$\quad \begin{array}{l}\text { Colony productivity } \\
\text { (1) Production of workers }\end{array}$ & & \\
$\quad \begin{array}{l}\text { Number of worker larvae } \\
\text { Larvae to eggs ratio }\end{array}$ & 2.01 & 0.16 \\
$\quad$ (2) Production of queens and males & 0.97 & 0.97 \\
$\quad$ Number of males & 1.42 & 0.48 \\
$\quad$ Number of queens & 0.58 & 0.31 \\
$\quad$ Investment in queens and males & 1.05 & 0.91 \\
\hline
\end{tabular}




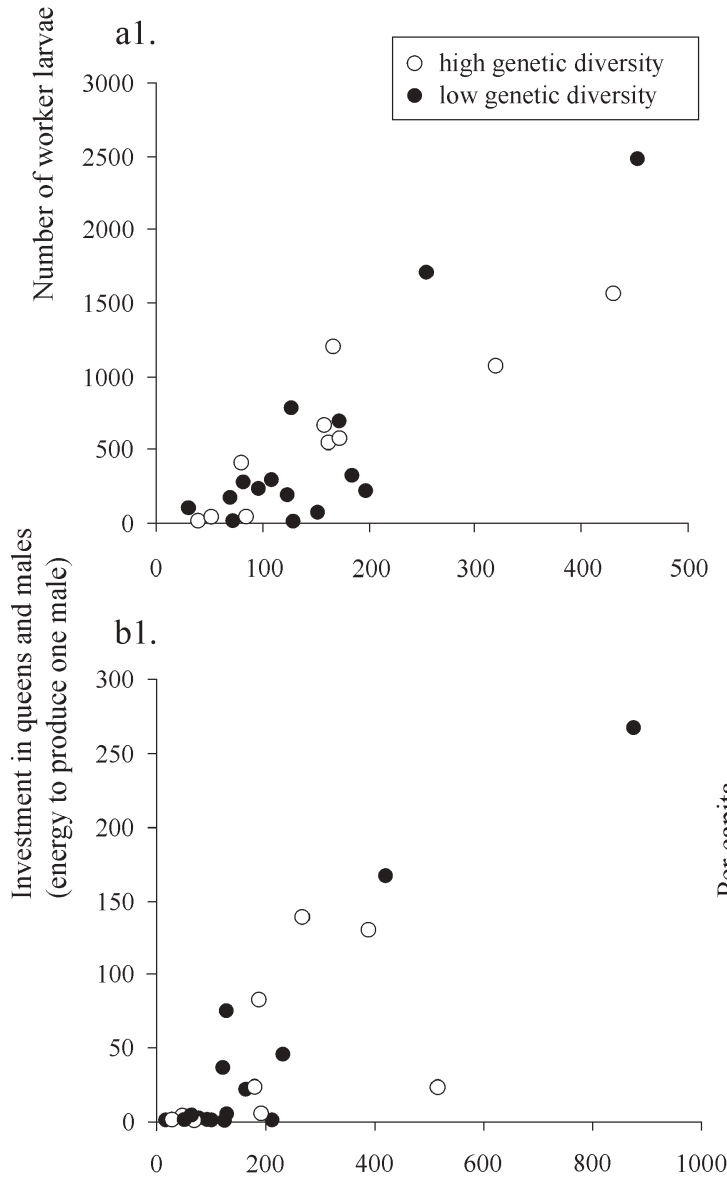

Fig. 4 Productivity of colonies with low and high genetic diversity as a function of colony size. a1 Number of worker larvae produced in queenright colonies. a2 Per capita number of worker larvae

Hence, our experiment provides no support for the taskefficiency hypothesis.

The statistical power of the analysis was sufficient to detect large effects of colony genetic diversity on shortterm task efficiency. An increase of $40 \%$ in any of the seven indicators of task efficiency would have been detected with an average probability of 0.85 . Such an increase in performance is considerable, but falls within the range of the effect that genetic diversity had on colony productivity in other social-insect species (Fuchs and Schade 1994; Baer and Schmid-Hempel 1999). The observed effect sizes and differences between treatments were small to moderate for most measures of task efficiency, except for the time to create a trail during nest emigration. There was no consistent pattern with respect to the hypothesis that high genetic diversity colonies should perform better: high genetic diversity colonies performed non-significantly better than low-diversity colonies in three cases, and worse in three other cases. Moreover, none of the seven indicators of efficiency were significant even before applying the Bonferroni adjustment for multiple comparisons. Together, these data show

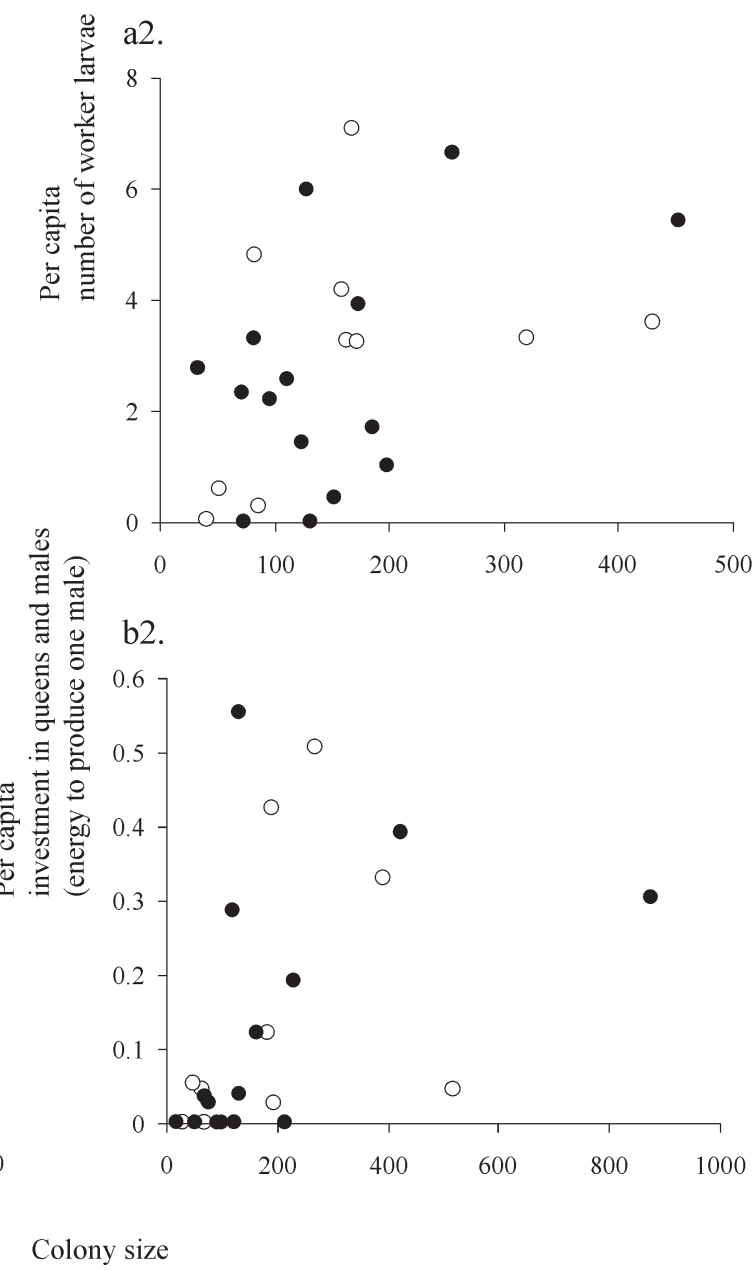

produced. b1 Investment in queens and males in queenless colonies. b2 Per capita investment in queens and males.

that genetic diversity had no major impact on task efficiency in our experiment. However, the statistical analysis had limited power to detect small effects. For example, our data suggest that colonies with high genetic diversity might be somewhat quicker than low-diversity colonies when establishing a new trail, but this difference was not statistically significant in our analysis. Colony genetic diversity may also have more impact on task efficiency at other levels of genetic variability, for other tasks, in other experimental conditions, or in other species.

We also found no support for the idea that a higher level of genetic diversity reduces the colony-level variance in task efficiency or productivity. This reduction in variance has been suggested to represent a bet-hedging strategy in a changing environment, as an average colony phenotype might be less likely to fail because of inappropriate behavioural response (Page et al. 1995). None of the 12 tests of variance were significant even before a Bonferroni adjustment, and no pattern was detected in the data. This study is the first to directly investigate the impact of genetic diversity on the variance of short-term task efficiency. Over longer time periods, genetic diver- 
sity was also not associated with a lower variance in colony productivity in the ant Lasius niger (Fjerdingstad et al. 2003). In the honeybee, during the nest-initiation phase, colonies where the queen had been experimentally inseminated with the semen of four males showed less variable performances than colonies headed by queens inseminated by the semen of a single drone (Page et al. 1995). However, there was no significant correlation between effective-mating frequency and the variance in honey yield or colony size in mature colonies headed by naturally mated queens (Neumann and Moritz 2000).

Taken together, our results suggest that high genetic diversity does not strongly improve short-term task efficiency in Linepithema humile. It is likely that a sufficient level of adaptive behavioural and developmental plasticity precedes changes in social structure, so that additional increase in genetic diversity due to multiple queens or unicoloniality has little impact on division of labour. Indeed, many social-insect species have colonies derived from one single-mated queen and nevertheless exhibit sophisticated behavioural repertoires with complex caste systems and pronounced division of labour (Oster and Wilson 1978). In line with this argument, a recent comparative analysis found no significant association between the level of polyandry and the prevalence of worker physical polymorphism or polyethism (Brown and Schmid-Hempel 2003).

Both the task-efficiency and parasite-resistance hypotheses predict that genetically more diverse colonies should be more productive. In our experiment, colony genetic diversity had no statistically significant impact on colony productivity. However, these tests had very low statistical power, the data show a trend in the predicted direction, and the observed effect sizes were relatively large in some cases. Moreover, the pressure of parasites might be stronger in the field than under laboratory conditions. Therefore, the fact that colony genetic diversity had no statistically significant impact on productivity in our experiment does not provide evidence against the task-efficiency or parasite-resistance hypotheses.

In contrast to genetic diversity, colony size was strongly and significantly positively correlated with most measures of task efficiency and colony productivity. Not surprisingly, colonies with more workers were quicker in creating a migration trail and, as a tendency, in exploring the territory. In addition, more workers were recruited to the food sources in larger colonies, which resulted in higher rates of food collection. However, both the percapita efficiency in collecting sugar water and the percentage of workers recruited at the baits did not vary with colony size, suggesting a linear effect of worker number. In Linepithema humile, the patterns of exploration and path formation vary adaptively with group size (Gordon 1995). Overall, larger groups of workers can retrieve more food and are better in competitive exploitation of the territory (Holway and Case 2001).

Colony productivity increased with colony size. Larger colonies had a higher ratio of larvae reared to eggs laid, and they also produced significantly more workers, queens and males. Obviously, large colonies can allocate a greater number of workers to brood-tending and foraging tasks. But interestingly, the per-capita productivity of workers also increased with colony size, which indicates synergetic interactions for brood-rearing. In particular, some small colonies failed to produce any brood, and most small colonies did not produce queens and males, suggesting a threshold size for reproduction, as has been documented in P. occidentalis (Cole and Wiernasz 2000). Larger colony size may also reduce stochastic variation and queuing delays, thus increasing the ergonomic efficiency of the colony (Anderson and Ratnieks 1999).

Colony size was not correlated with the time between food discovery and peak of workers recruitment, or with the duration of nest-moving. This is understandable, as a higher number of workers increases the importance of the task being measured. More surprisingly, there was no significant association between colony size and the speed at which corpses were removed. Only few workers are needed to achieve this task. It is possible that the number of workers involved in corpse removal is adapted to the number of dead workers to remove, independently of colony size. Such a precise allocation of workers to tasks might be regulated by positive or negative feedback loops. For example, harvester-ant workers have a higher probability of engaging in corpse or waste removal when the frequency of encounter with other workers doing this task is high (Gordon and Mehdiabadi 1999).

In conclusion, large colony size is probably a key factor determining the performance and competitive ability of this invasive ant species. Indeed, the loss of intraspecific aggression has allowed the formation of extremely populous supercolonies in the introduced range (Giraud et al. 2002; Tsutsui and Suarez 2003), which confers a strong competitive advantage (Holway et al. 1998, 2002; Holway and Case 2001). More generally, this study adds to the growing body of evidence showing that increased group size might provide direct benefits independently of genetic diversity or relatedness (CluttonBrock 2002; Costa and Ross 2003).

Acknowledgements This research was supported by the Swiss National Science Foundation (grant 31-61934.00 to M.C. and several grants to L.K.). We thank Lotta Sundström and the anonymous reviewers for comments on the manuscript.

\section{References}

Anderson C, Ratnieks FLW (1999) Task partitioning in insect societies. I. Effect of colony size on queueing delay and colony ergonomic efficiency. Am Nat 154:521-535

Baer B, Schmid-Hempel P (1999) Experimental variation in polyandry affects parasite loads and fitness in a bumble-bee. Nature 397:151-154

Baer B, Schmid-Hempel P (2001) Unexpected consequences of polyandry for parasitism and fitness in the bumblebee, Bombus terrestris. Evolution 55:1639-1643

Benois A (1973) Incidences des facteurs écologiques sur le cycle annuel et l'activité saisonnière de la fourmi d'Argentine Ir- 
idomyrmex humilis (Mayr) (Hymenoptera, Formicidae), dans la région d'Antibes. Insectes Soc 20:267-296

Beshers SN, Fewell JH (2001) Models of division of labor in social insects. Annu Rev Entomol 46:413-440

Boomsma JJ, Ratnieks FLW (1996) Paternity in eusocial Hymenoptera. Philos Trans R Soc Lond B 351:947-975

Bourke AFG, Franks NR (1995) Social evolution in ants. Princeton University Press, Princeton

Brown MJF, Schmid-Hempel P (2003) The evolution of female multiple mating in social hymenoptera. Evolution 57:20672081

Cahan SH, Keller L (2003) Complex hybrid origin of genetic caste determination in harvester ants. Nature 424:306-309

Cahan SH, Parker JD, Rissing SW, Johnson RA, Polony TS, Weiser MD, Smith DR (2002) Extreme genetic differences between queens and workers in hybridizing Pogonomyrmex harvester ants. Proc R Soc Lond B 269:1871-1877

Carlin NF, Reeve HK, Cover SP (1993) Kin discrimination and division of labour among matrilines in the polygynous carpenter ant, Camponotus planatus. In: Keller L (ed) Queen number and sociality in insects. Oxford University Press, Oxford, pp 362-401

Clutton-Brock T (2002) Breeding together: kin selection and mutualism in cooperative vertebrates. Science 296:69-72

Cohen J (1988) Statistical power analysis for the behavioral sciences. Erlbaum, Hillsdale, NJ

Cole BJ, Wiernasz DC (1999) The selective advantage of low relatedness. Science 285:891-893

Cole BJ, Wiernasz DC (2000) Colony size and reproduction in the western harvester ant, Pogonomyrmex occidentalis. Insectes Soc 47:249-255

Costa JT, Ross KG (2003) Fitness effects of group merging in a social insect. Proc R Soc Lond B 270:1697-1702

Crozier RH, Fjerdingstad EJ (2001) Polyandry in social Hymenoptera-disunity in diversity? Ann Zool Fenn 38:267-285

Crozier RH, Page RE (1985) On being the right size: male contributions and multiple mating in social Hymenoptera. Behav Ecol Sociobiol 18:105-115

Crozier RH, Pamilo P (1996) Evolution of social insect colonies: sex allocation and kin selection. Oxford University Press, Oxford

El Mousadik A, Petit RJ (1996) High level of genetic differentiation for allelic richness among populations of the argan tree [Argania spinosa (L.) Skeels] endemic to Morocco. Theor Appl Genet 92:832-839

Erdfelder E, Faul F, Buchner A (1996) GPOWER: a general power analysis program. Behav Res Methods Instrum Comput 28:111

Fjerdingstad EJ, Gertsch PJ, Keller L (2003) The relationship between multiple mating by queens, within-colony genetic variability and fitness in the ant Lasius niger. J Evol Biol 16:844853

Fraser VS, Kaufmann B, Oldroyd BP, Crozier RH (2000) Genetic influence on caste in the ant Camponotus consobrinus. Behav Ecol Sociobiol 47:188-194

Frumhoff PC, Baker J (1988) A genetic component to division of labour within honey bee colonies. Nature 333:358-361

Fuchs S, Schade V (1994) Lower performance in honeybee colonies of uniform paternity. Apidologie 25:155-168

Giraud T, Pedersen JS, Keller L (2002) Evolution of supercolonies: the Argentine ants of southern Europe. Proc Natl Acad Sci USA 99:6075-6079

Gordon DM (1995) The expandable network of ant exploration. Anim Behav 50:995-1007

Gordon DM, Mehdiabadi NJ (1999) Encounter rate and task allocation in harvester ants. Behav Ecol Sociobiol 45:370-377

Goudet J (1995) FSTAT (Version 1.2): a computer program to calculate F-statisics. J Hered 86:485-486

Holway DA (1999) Competitive mechanisms underlying the displacement of native ants by the invasive Argentine ant. Ecology $80: 238-251$
Holway DA, Case TJ (2000) Mechanisms of dispersed centralplace foraging in polydomous colonies of the Argentine ant Anim Behav 59:433-441

Holway DA, Case TJ (2001) Effects of colony-level variation on competitive ability in the invasive Argentine ant. Anim Behav 61:1181-1192

Holway DA, Suarez AV, Case TJ (1998) Loss of intraspecific aggression in the success of a widespread invasive social insect. Science 282:949-952

Holway DA, Lach L, Suarez AV, Tsutsui ND, Case TJ (2002) The causes and consequences of ant invasions. Annu Rev Ecol Syst 33:181-233

Hughes WOH, Boomsma JJ (2004) Genetic diversity and disease resistance in leaf-cutting ant societies. Evolution 58:1251-1260

Hughes WOH, Sumner S, Van Borm S, Boomsma JJ (2003) Worker caste polymorphism has a genetic basis in Acromyrmex leaf-cutting ants. Proc Natl Acad Sci USA 100:9394-9397

Human KG, Gordon DM (1996) Exploitation and interference competition between the invasive argentine ant, Linepithema humile, and native ant species. Oecologia 105:405-412

Human KG, Gordon DM (1999) Behavioral interactions of the invasive Argentine ant with native ant species. Insectes Soc 46:159-163

Ingram KK (2002) Flexibility in nest density and social structure in invasive populations of the Argentine ant, Linepithema humile. Oecologia 133:492-500

Jones JC, Myerscough MR, Graham S, Oldroyd BP (2004) Honey bee nest thermoregulation: diversity promotes stability. Science 305:402-404

Julian GE, Cahan S (1999) Undertaking specialization in the desert leaf-cutter ant Acromyrmex versicolor. Anim Behav 58:437442

Julian GE, Fewell JH, Gadau J, Johnson RA, Larrabee D (2002) Genetic determination of the queen caste in an ant hybrid zone. Proc Natl Acad Sci USA 99:8157-8160

Keller L, Chapuisat M (1999) Cooperation among selfish individuals in insect societies. Bioscience 49:899-909

Keller L, Chapuisat M (2001) Eusociality and cooperation. Nature Encyclopedia of Life Sciences, http://www.els.net/. Nature, London

Keller L, Reeve HK (1994) Genetic variability, queen number, and polyandry in social hymenoptera. Evolution 48:694-704

Keller L, Cherix D, Ulloa-Chacón P (1989a) Description of a new artificial diet for rearing ant colonies as Iridomyrmex humilis, Monomorium pharaonis and Wasmannia auropunctata (Hymenoptera; Formicidae). Insectes Soc 36:348-352

Keller L, Passera L, Suzzoni JP (1989b) Queen execution in the Argentine ant Iridomyrmex humilis (Mayr). Physiol Entomol 14:157-163

Kraus B, Page RE (1998) Parasites, pathogens, and polyandry in social insects. Am Nat 151:383-391

Krieger MJB, Keller L (1999) Low polymorphism at $19 \mathrm{mi}-$ crosatellite loci in a French population of Argentine ants (Linepithema humile). Mol Ecol 8:1078-1080

Krieger MJB, Keller L (2000) Mating frequency and genetic structure of the Argentine ant Linepithema humile. Mol Ecol 9:119-126

Liersch S, Schmid-Hempel P (1998) Genetic variation within social insect colonies reduces parasite load. Proc R Soc Lond B 265:221-225

Neumann P, Moritz RFA (2000) Testing genetic variance hypotheses for the evolution of polyandry in the honeybee (Apis mellifera L.). Insectes Soc 47:271-279

Oldroyd BP, Rinderer TE, Harbo JR, Buco SM (1992) Effects of intracolonial genetic diversity on honeybee (Hymenoptera: Apidae) colony performances. Ann Entomol Soc Am 85:335343

Oldroyd BP, Sylvester HA, Wongsiri S, Rinderer TS (1994) Task specialization in a wild bee, Apis florea (Hymenoptera: Apidae), revealed by RFLP banding. Behav Ecol Sociobiol 34:2530 
Oster GF, Wilson EO (1978) Caste and ecology in the social insects. Princeton University Press, Princeton

Page RE, Erber J (2002) Levels of behavioral organization and the evolution of division of labor. Naturwissenschaften 89:91-106

Page RE, Robinson GE, Fondrk MK, Nasr ME (1995) Effects of worker genotypic diversity on honey bee colony development and behavior (Apis mellifera L.). Behav Ecol Sociobiol 36:387396

Palmer KA, Oldroyd BP (2003) Evidence for intra-colonial genetic variance in resistance to American foulbrood of honey bees (Apis mellifera): further support for the parasite/pathogen hypothesis for the evolution of polyandry. Naturwissenschaften 90:265-268

Passera L (1994) Characteristics of tramp species. In: Williams DF (ed) Exotic ants biology, impact, and control of introduced species. Westview, Boulder, Colo, pp 23-43

Passera L, Keller L (1987) Energy investment during the differentiation of sexuals and workers in the Argentine ant Iridomyrmex humilis (Mayr). Mitt Schweiz Entomol Ges 60:249260

Passera L, Keller L, Suzzoni J-P (1988) Control of brood male production in the Argentine ant Iridomyrmex humilis (Mayr). Insectes Soc 35:19-33

Queller DC, Goodnight KF (1989) Estimating relatedness using genetic markers. Evolution 242:258-275

Queller DC, Strassmann JE (2002) The many selves of social insects. Science 296:311-313

Rice WR (1989) Analyzing tables of statistical tests. Evolution 43:223-225

Robinson GE (1992) Regulation of division of labor in insect societies. Annu Rev Entomol 37:637-665

Robinson GE, Page RE (1988) Genetic determination of guarding and undertaking in honey-bee colonies. Nature 333:356-358

Schmid-Hempel P, Crozier RH (1999) Polyandry versus polygyny versus parasites. Philos Trans R Soc Lond B 354:507-515
Sherman PW, Seeley TD, Reeve HK (1988) Parasites, pathogens, and polyandry in social Hymenoptera. Am Nat 131:602-610

Sherman PW, Seeley TD, Reeve HK (1998) Parasites, pathogens, and polyandry in honey bees. Am Nat 151:392-396

Starr CK (1984) Sperm competition, kinship, and sociality in the aculeate Hymenoptera. In: Smith RL (ed) Sperm competition and the evolution of animal mating systems. Academic, Orlando, Fla, pp 427-464

Stuart RJ, Page RE (1991) Genetic component to division of labor among workers of a leptothoracine ant. Naturwissenschaften 78:375-377

Suarez AV, Holway DA, Case TJ (2001) Patterns of spread in biological invasions dominated by long-distance jump dispersal: insights from Argentine ants. Proc Natl Acad Sci USA 98:1095-1100

Sundström L, Ratnieks FLW (1998) Sex ratio conflicts, mating frequency, and queen fitness in the ant Formica truncorum. Behav Ecol 9:116-121

Tarpy DR (2003) Genetic diversity within honeybee colonies prevents severe infections and promotes colony growth. Proc R Soc Lond B 270:99-103

Tsutsui ND, Case TJ (2001) Population genetics and colony structure of the argentine ant (Linepithema humile) in its native and introduced ranges. Evolution 55:976-985

Tsutsui ND, Suarez AV (2003) The colony structure and population biology of invasive ants. Conserv Biol 17:48-58

Vargo EL, Passera L (1991) Pheromonal and behavioral queen control over the production of gynes in the Argentine ant $I r$ idomyrmex humilis (Mayr). Behav Ecol Sociobiol 28:161-169

Volny VP, Gordon DM (2002) Genetic basis for queen-worker dimorphism in a social insect. Proc Natl Acad Sci USA 99:6108-6111

Wiernasz DC, Perroni CL, Cole BJ (2004) Polyandry and fitness in the western harvester ant, Pogonomyrmex occidentalis. Mol Ecol 13:1601-1606 